\title{
EDUCAÇÃO AMBIENTAL COMO FERRAMENTA DE ENSINO
}

\author{
Bruna Lima Macedo ${ }^{1}$ \\ Vivianne Fleury de Faria ${ }^{2}$
}

Resumo: As temáticas ambientais estâo cada vez mais presentes no cotidiano e vem ganhando seu espaço dentro do sistema de ensino, uma vez que o público encontra-se mais receptivos a estas abordagens. Diante deste contexto o seguinte estudo visa inserir a educação ambiental no âmbito escolar como uma ferramenta a proporcionar o desenvolvimento da consciência ambiental e pensamento crítico por meio da ação educativa. O projeto "Semana da Ecologia e Sustentabilidade" foi desenvolvido no Centro de Ensino e Pesquisa Aplicado à Educação- CEPAE vinculado a Universidade Federal de Goiás (UFG), a intervenção trabalhou com meios que proporcionam a participação e interaçáo dos alunos e reflexáo sobre a importância da conservaçáo do meio ambiente e as problemáticas enfrentadas pela sua conservação. As ações buscaram inserir abordagens didáticas e lúdicas como estratégia de ensino de acordo com a linguagem adequada às diversas faixas etárias, a fim de proporcionar uma melhor compreensáo e participação dos alunos. O projeto foi realizado através de palestras, peças teatrais, documentários, mostra de curtas e fotografias. Em busca de uma fixação e explanação sobre os conteúdos abordadas foram realizadas atividades desenvolvidas pelos alunos para serem expostos ao público como material resultantes da ação de educação ambiental. Todas as atividades visaram contemplar todos os níveis de ensino, básico, médio e fundamental, além de ampliar aos professores, pais e comunidade do entorno, contabilizando cerca de 800 pessoas alcançadas pelas açóes.

Palavras-chave: Ensino, Ação Educativa, Educação Ambiental, Meio Ambiente, Conscientização.

\section{ENVIRONMENTAL EDUCATION AS A TEACHING TOOL}

\begin{abstract}
The environmental themes are increasingly present in everyday life and have been gaining space within the education system, since the public is more receptive to the approaches. Given this context, the following study aims to include environmental education in the school as a tool to provide the development of environmental awareness and critical thinking through educational action. The project "Week of Ecology and Sustainability" was developed at the Center for Education and Research Applied to Education - CEPAE linked to the Federal University of Goiás (UFG),
\end{abstract}

1 Graduanda do Curso de Ciências Ambientais da UFG. Professora Dra Vivianne Fleury de Faria (CEPAE/ UFG). bruna.limamacedo0128@gmail.com

2 Doutora em Literatura Brasileira pela Universidade de Brasília (2007). Mestre em Estudos Literários pela Universidade Federal de Goiás (2000). Professora Adjunta III de Língua Portuguesa do CEPAE/ UFG (2010). 
the intervention worked with means that provide the participation and interaction of students and reflection on the importance Conservation of the environment and the problems faced by it. The actions sought to introduce didactic and playful approaches as a teaching strategy according to the appropriate language to the different age groups, in order to provide a better understanding and participation of the students. The same was done through lectures, plays, documentaries, short shows and photographs. In search of a fixation and explanation about the contents approached were carried out activities developed by the students to be exposed to the public as material resulting from the action of environmental education. All activities aimed at contemplating all levels of education, basic, middle and fundamental, in addition to expanding teachers, parents and community around, accounting for about 800 people achieved by actions.

Keywords: Educational Action, Schools, Environmental Education, Environment, Awareness.

\section{INTRODUÇÃO}

A temática ambiental vem sendo contemplada sob seus diversos aspectos em meios múltiplos, proporcionando uma reflexão cuja finalidade está no despertar de um saber ambiental. Diante de um cenário cada vez mais fragilizado, a disseminação de conhecimentos torna-se essencial e indispensável para compreender e transformar a realidade exploratória e degradada do meio ambiente atualmente.

Conflitos foram desencadeados ao longo do tempo, decorrentes da interrelação não harmônica entre o sistema econômico, sociedade e natureza. A apropriação da natureza e os diversos valores atribuídos aos recursos naturais resultaram em uma má gestão dos mesmos e em ações cada vez mais predatórias e impactantes para o meio ambiente, tornando, assim, a qualidade ambiental vulnerável e precária.

Ao considerar a atual conjuntura, reverter as condições vivenciadas tornase prioridade, uma vez que este é um momento culminante para transformações que sejam capazes de combater condições ambientais problematizadas. Diante disso, proporcionar o conhecimento a respeito de um saber ambiental permite uma reflexão fundamental para adquirir princípios baseados em uma relação harmônica e de menor impacto possível com o meio ambiente.

Exatamente durante o processo da disseminação de conhecimento que o sistema educacional entra como o meio facilitador e fundamental, uma vez que este é responsável pelo processo de construção de saberes. A escola e o sistema de ensino permitem uma inserção de conhecimentos diversos através de ações coletivas e individuais, despertando assim interpretações, ações e interações capazes de formar indivíduos conscientes e proporcionar mudanças comportamentais quanto a sua relação com o meio ambiente.

O êxito está na construção de uma relação integrada e harmônica que priorize e busque a conservação e preservação ambiental. A percepção se inicia desde práticas individuais e ações cotidianas até interações coletivas e ações em longo prazo, ou seja, a partir daí se dá a internalização dos ideais que permitem recriar e/ou readaptar novos hábitos em prol do cuidado com o meio ambiente. 
Com efeito, a Educação ambiental é uma ferramenta que permite abordar as diversas dimensões ambientais, considerando a aprendizagem como um processo de construção do conhecimento e de constantes aprimoramentos. A inserção da Educação Ambiental (E.A) nas escolas permite associar o ambiente de ensino á abordagem de temáticas ambientais através de diversas formas englobadas nas mais variadas disciplinas.

De acordo com o Art. $1^{\circ}$ da Lei da Educação Ambiental, entendem-se por educação ambiental os processos por meio dos quais o indivíduo e a coletividade constroem valores sociais, conhecimentos, habilidades, atitudes e competências voltadas para a conservação do meio ambiente, bem de uso comum do povo, essencial à sadia qualidade de vida e sua sustentabilidade.

A articulação sobre E.A se iniciou no ano de 1972 na Conferência de Estocolmo quando foram abordados ressalvas e discernimentos quanto ao quadro caótico vivenciado no meio ambiental e as responsabilidades socioambientais de cada indivíduo quanto a tais questões. Contudo, a contemplação das práticas e inserção da Educação ambiental só teve início a partir da Conferência Intergovernamental sobre Educação Ambiental realizada em Tsibilisi (EUA), em 1977, sendo uma das ações de extrema relevância, uma vez que considerou os diversos aspectos da E.A, além das orientações e alternativas para adequar a natureza da mesma.

Considerando a extrema relevância das escolas nos processo de formação dos cidadãos e a importância de explorar diversas temáticas que devem ser abordadas, a autora Reigota (1998) ressalta bem o papel das escolas.

A escola tem sido historicamente o espaço indicado para a discussão e o aprendizado de vários temas urgentes e de atualidade, como resultado da sua importância na formação dos cidadãos. Evidentemente que a escola deve estar sempre aberta ao conhecimento, inquietações e propostas de sua época, e procurar consolidar inovações pedagógicas que contribuam para que a mesma continue cumprindo com seu papel social. (REIGOTA, 1998, p.47).

Entretanto, a Educação Ambiental deve ser inserida nos diversos níveis de ensino, considerando que o processo de aprendizagem é constante, a contemplação desta abordagem deve se estender a todos. De acordo com a Constituição da Republica Federativa do Brasil de 1988:

Art. 225. Todos têm direito ao meio ambiente ecologicamente equilibrado, bem de uso comum do povo e essencial à sadia qualidade de vida, impondose ao poder público e à coletividade o dever de defendê-lo e preservá-lo para os presentes e futuras gerações.

$\int 1^{\circ}$ - Para assegurar a efetividade desse direito, incumbe ao poder público:

VI - promover a educação ambiental em todos os níveis de ensino e a conscientização pública para a preservação do meio ambiente

Posteriormente com a criação da Lei de Educação Ambiental (1999) reafirmou-se a inserção da E.A no ensino no Brasil. 
Art. $2^{\circ}$ A educação ambiental é um componente essencial e permanente da educação nacional, devendo estar presente, de forma articulada, em todos os níveis e modalidades do processo educativo, em caráter formal e não formal.

De acordo com a contextualização, o seguinte trabalho contempla a utilização da E.A como ferramenta de ensino, e teve sua aplicabilidade através do projeto de extensão e cultura "Semana da Ecologia e Sustentabilidade" desenvolvida no Centro de Ensino e Pesquisa Aplicada à Educação- CEPAE/ UFG.

\section{OBJETIVOS}

Contemplar a aplicação da Educação Ambiental como ferramenta para transformar a consciência, promovendo a difusão de valores ambientais entre professores, alunos e comunidade do entorno que participaram direta ou indiretamente das intervenções realizadas além de despertar através das atividades desenvolvidas uma mudança comportamental.

\section{METODOLOGIA}

Partindo da inserção de propostas ambientais no cotidiano dos alunos, a metodologia se baseou nas abordagens ambientais de diversas temáticas (degradação ambiental, agroecologia, reciclagem, solo, água, conservação do cerrado) através de ações como palestras, mostra de curtas, peças teatrais, exposição fotográfica. Posteriormente as ações foram executadas pelos alunos dissertações, concurso de redação, poemas e fotografias.

A intervenção foi realizada com turmas do ensino básico e médio, com alunos de 7 a 18 anos, com a finalidade de contemplar as diversas faixas etárias, além de expandir para o público externo e integrá-los por meio do conhecimento sobre os diversos aspectos ambientais. Todas as etapas contaram com a participação direta ou indiretamente de colaboradores. Para a execução do projeto realizouse um planejamento com base no cronograma de temáticas a serem trabalhadas (TABELA 1).

Tabela 1

\begin{tabular}{|c|c|c|c|c|}
\hline \multicolumn{5}{|c|}{ PLANO DE ATIVIDAES - MÊS DE ABRIL } \\
\hline DATA & TURMAS & HORÁRIO & ATIVIDADE & PALESTRA \\
\hline $\begin{array}{c}06 / 04 \\
\text { (Quinta-Feira) }\end{array}$ & $\begin{array}{c}9^{\circ} \text { ano } \\
\text { (Prof. }{ }^{a} \text { Célia) }\end{array}$ & $\begin{array}{c}1^{\circ} \text { e } 2^{\circ} \text { aula }-9^{\circ} \mathrm{B}(7: 30 \text { às } \\
9: 00) \\
5^{\circ} \text { e } 6^{\circ} \text { aula }-9^{\circ} \mathrm{A}(10: 45 \text { às } \\
12: 30)\end{array}$ & $\begin{array}{l}\text { MOSTRA DE } \\
\text { CURTAS }\end{array}$ & LISBETH \\
\hline $\begin{array}{c}10 / 04 \\
\text { (Segunda-Feira) }\end{array}$ & $\begin{array}{c}3^{\circ} \text { ano } \\
\text { (Prof. Ise) }\end{array}$ & $\begin{array}{c}1^{\circ} \text { e } 2^{\circ} \text { aula }-3^{\circ} \mathrm{A}(7: 30 \text { ás } \\
9: 00) \\
3^{\circ} \text { e } 4^{\circ} \text { aula }-3^{\circ} \mathrm{B}(- \text { as }-)\end{array}$ & $\begin{array}{l}\text { PALESTRA SOLO } \\
\text { NA ESCOLA }\end{array}$ & RENATA M. \\
\hline $\begin{array}{c}20 / 04 \\
\text { (Quinta-Feira) }\end{array}$ & $\begin{array}{c}2^{\circ} \text { ano } \\
\text { (Prof. }{ }^{a} \text { Vivianne) }\end{array}$ & $\begin{array}{c}1^{\circ} \text { e } 2^{\circ} \text { aula }-2^{\circ} \mathrm{A}(7: 30 \text { ás } \\
9: 00) \\
\begin{array}{c}5^{\circ} \text { e } 6^{\circ} \text { aula }-2^{\circ} \mathrm{B}(10: 45 \text { às } \\
12: 30)\end{array}\end{array}$ & $\begin{array}{c}\text { PALESTRA } \\
\text { DEGRADAÇÃO } \\
\text { AMBIENTAL }\end{array}$ & PEDRO BAIMA \\
\hline
\end{tabular}




\begin{tabular}{|c|c|c|c|c|}
\hline $\begin{array}{c}27 / 04 \\
\text { (Quinta-Feira) }\end{array}$ & $\begin{array}{c}6^{\circ} \text { ano } \\
\text { (Prof. }{ }^{\text {a Elisandra) }}\end{array}$ & $\begin{array}{l}1^{\circ} \text { e } 2^{\circ} \text { aula }-6^{\circ} \mathrm{B}(7: 30 \text { ás } \\
\quad 9: 00) \\
4^{\circ} \text { e } 5^{\circ} \text { aula }-6^{\circ} \mathrm{A}(- \text { as }-)\end{array}$ & PALESTRA ONG & $\begin{array}{c}\text { ONG ALIANÇA DA } \\
\text { TERRA }\end{array}$ \\
\hline \multirow{2}{*}{$\begin{array}{c}28 / 07 \\
\text { (Sexta-Feira) }\end{array}$} & $\begin{array}{c}8^{\circ} \text { ano } \\
\text { (Prof. }{ }^{a} \text { Deise) }\end{array}$ & $\begin{array}{c}1^{\circ} \text { e } 2^{\circ} \text { aula }-8^{\circ} \mathrm{A}(7: 30 \text { ás } \\
9: 00) \\
5^{\circ} \text { e } 6^{\circ} \text { aula }-8^{\circ} \mathrm{B}(10: 45 \text { às } \\
12: 30)\end{array}$ & PEÇA TEATRAL & BRUNO \\
\hline & $2^{\circ}$ e $3^{\circ}$ ano & 14 horas - Cine UFG & $\begin{array}{l}\text { MOSTRA DE } \\
\text { CURTAS }\end{array}$ & JOÃO NOVAES \\
\hline \multicolumn{5}{|c|}{ PLANO DE ATIVIDAES - MÊS DE MAIO } \\
\hline $\begin{array}{c}04 / 05 \\
\text { (Quinta-Feira) }\end{array}$ & $\begin{array}{c}9^{\circ} \text { ano B (Prof. } \\
\text { Célia) } \\
2^{\circ} \text { ano A (Prof. } \\
\text { Vivianne) } \\
3^{\circ} \text { ano A (Prof. } \\
\text { Ise) }\end{array}$ & $1^{\circ}$ e $2^{\circ}$ aula - (7:30 ás 9:00) & $\begin{array}{c}\text { PALESTRA } \\
\text { CONSERVAÇÃO } \\
\text { DO CERRADO }\end{array}$ & AMMA \\
\hline $\begin{array}{c}10 / 05 \\
\text { (Quarta-Feira) }\end{array}$ & $\begin{array}{c}1^{\circ} \text { ano } \\
\text { (Prof. }{ }^{\mathrm{a}} \text { Luzia) }\end{array}$ & $\begin{array}{c}1^{\circ} \text { e } 2^{\circ} \text { aula }-1^{\circ} \mathrm{B}(7: 30 \text { às } \\
9: 00) \\
5^{\circ} \text { e } 6^{\circ} \text { aula }-1^{\circ} \mathrm{A}(10: 45 \text { às } \\
12: 30)\end{array}$ & $\begin{array}{c}\text { PALESTRA } \\
\text { RECICLAGEM }\end{array}$ & $\begin{array}{l}\text { FERNANDO - } \\
\text { INCUBADORA } \\
\text { SOCIAL UFG }\end{array}$ \\
\hline $\begin{array}{c}19 / 05 \\
\text { (Sexta-Feira) }\end{array}$ & $2^{\circ}$ e $3^{\circ}$ ano & 14 horas - Cine UFG & $\begin{array}{l}\text { MOSTRA DE } \\
\text { CURTA } \\
\text { EXPOSIÇÃO DE } \\
\text { FOTOS }\end{array}$ & $\begin{array}{l}\text { JOÃO NOVAES } \\
\text { LUIS FERNANDO }\end{array}$ \\
\hline $\begin{array}{c}20 / 05 \\
\text { (Sábado) }\end{array}$ & $\begin{array}{l}\text { PIPOESIA } \\
\text { (Todos) }\end{array}$ & $8: 00-12: 00$ & $\begin{array}{l}\text { PEÇA TEATRAL } \\
\text { (TEATRO- } \\
\text { FÓRUM) }\end{array}$ & $\begin{array}{l}\text { JÕAO DAMASIO } \\
\text { (COLETIVO } \\
\text { JOVEM DE MEIO } \\
\text { AMBIENTE) }\end{array}$ \\
\hline
\end{tabular}

De acordo com o plano de ensino elaborado inicialmente, a primeira atividade realizou-se simultaneamente para os alunos do ensino básico e ensino médio, com a finalidade de abordar o tema Meio Ambiente de forma geral, como uma alternativa de despertar e instigar o pensamento dos alunos sobre o assunto.

Sendo assim, foi realizada uma mostra de documentários exibida para os alunos do ensino médio. Os documentários selecionados foram "Biomas Brasileiros: Cerrado", de Paulo Newton (2014), e " O Mundo Segundo a Monsanto", dirigido e produzido por Marie Monique Robin (2008), contando com a participação de debatedores convidados para explorar e discorrer sobre as temáticas o professor do Cepae Glauco Roberto Gonçalves, doutor em Geografia Humana pela USP, e Maurivan Vaz Ribeiro, membro do Instituto Boitatá de Etnobiologia e Conservação da Fauna.

O ensino básico - com turmas de $1^{\mathrm{a}}$ a $4^{\mathrm{a}}$ séries - participou da atividade prática "Um dia de campo na escola" com a finalidade de abordar as diversas temáticas ambientais por meio de atividades lúdicas e dinâmicas, com propósito de enquadrar a ação ao método mais propício para a compreensão e absorção do conteúdo pelos alunos, se adequando de acordo com a faixa etária.

A atividade contou com a participação de convidados voluntários, dentre estes a Gaia- Consultoria Ambiental Jr (Empresa Junior do Instituto de Estudo Socioambiental), e a Professora Dr Renata Santos Momoli, do Instituto de Estudo 
Socioambiental. Foram expostos experimentos, jogos, pinturas com solo e curtas de animação, permitindo a interação das crianças com as temáticas através de explicações e questionamentos que permitiram a reflexão e correlação das praticas diárias com efeitos impactantes causados ao meio ambiente. (Imagem 1)

Imagem 1. Atividades desenvolvidas na primeira etapa da intervenção

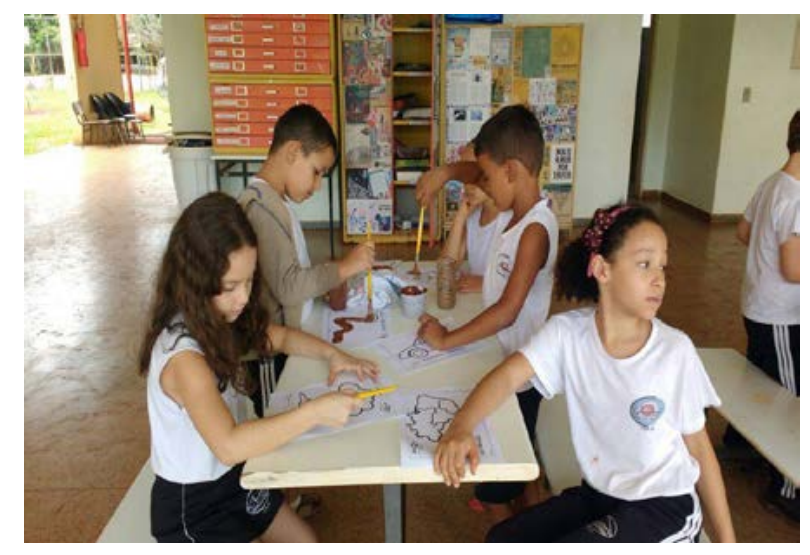

A segunda etapa do projeto contou com as atividades que permitiram o aprofundamento do conhecimento acerca das temáticas, uma vez que estes já haviam se deparado de forma geral com o conteúdo na fase anterior.

Esta etapa contou com diversos colaboradores que participaram direta ou indiretamente, permitindo assim que o projeto tivesse o êxito desejado. Dentre os colaboradores estão Professores do Instituto de Estudo Socioambiental e da Faculdade de Comunicação e Biblioteconomia da UFG, Fotógrafo, ONG. Aliança da Terra, colaboradores do Movimento Nacional do Coletivo Jovem do meio Ambiente e a Incubadora Social da UFG.

Dentre as atividades desenvolvidas estão Mostra de curta, coordenada pela professora Lisbethe Oliveira (Faculdade de Comunicação e Biblioteconomia - UFG) visando abordar princípios do consumo consciente e contemplar o "Alimento" como foco principal. Abrangendo os diversos aspectos do tema dentre eles, utilização de insumos químicos na agricultura, agrotóxicos e os malefícios resultantes dessa aplicação, alimentos transgênicos e, em contrapartida, abordar ações alternativas, como agricultura sustentável, agroecologia, adubação verde e processo de compostagem A atividade contou com a exibição de filmes de animação: "Tomatoes Terminators" e "O verdadeiro custo do alimento", além de apresentar o Manual de Educação - Consumo Sustentável (2005), como material de suporte.

Posteriormente seguindo uma sequência temática para a correlação dos tópicos abordados, foi realizada a palestra sobre solos, conduzida pela Professora Dr. Renata Santos Momoli (Instituto de Estudo Socioambiental - IESA/ UFG), coordenadora do projeto "Solo nas Escolas", cuja finalidade foi a de levar o conhecimento a respeito desse recurso natural em todos os aspectos. A abordagem 
variou desde o processo e fatores de formação, elementos que o compõem, os diversos tipos de solo existentes, a importância da preservação do mesmo diante da sua extrema importância em inúmeros aspectos. Além destas abordagens, o processo de degradação e impactos ambientais também foi levantado, contando com experimentos e demonstrações dos modelos didáticos aos alunos.

Outro tema de suma relevância abordado foi a "Água", por meio de palestra ministrada por Ana Lílian, Analista Ambiental da ONG. Aliança da Terra. Dentre os diversos elementos a serem abordados dentro desta temática, receberam destaque o ciclo hidrográfico, nascentes e bacias hidrográficas, a distribuição e consumo de água doce e seus diversos usos, levando a reflexão dos alunos durante o debate quanto ao consumo consciente, a importância do cuidado com as nascentes e bacias.

Uma abordagem mais didática, que objetivava a contemplação histórica e cultural dos indígenas nas escolas, foi a apresentação da peça teatral "Origem em Lendas" (Imagem 2), dirigido por Maria Angela de Ambrosis, com a finalidade de explorar as crenças, valores e a relação harmônica e dependente dos povos indígenas com o meio ambiente (Espetáculo realizado por Bruno Pina de Souza). Além destes elementos, a peça contemplou as mudanças da relação homem-natureza no tempo, os aspectos negativos da nova interação e as interferências sobre o mesmo.

\section{Imagem 2. Peça teatral "Origem em Lendas"}

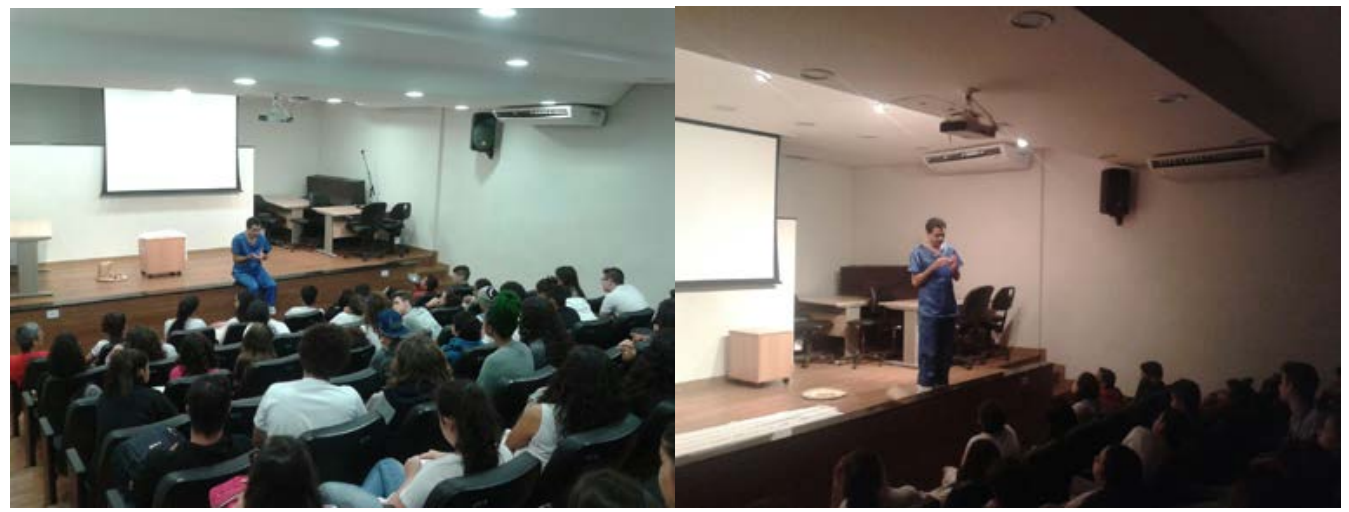

Para o fechamento das ações foi apresentada outra peça teatral "A Saga de Zéca Brejeiro", conduzida pelo "Coletivo Jovem do Meio Ambiente"; uma mostra de curtas com temática ambiental, com a curadoria de João Novaes, e uma mostra fotográfica sobre o Xingu, do fotógrafo Luis Filipe Macedo. Todas as atividades contaram com a participação de alunos, professores, pais, outras instituições de ensino e comunidade externa, uma vez que o evento era aberto para o público com o intuito de não restringir apenas a escola local, mas abranger os diversos públicos. O fechamento foi compilado ao evento PiPoesia, realizado no Cepae, contando com os participantes que prestigiaram todas as atividades de forma participativa, agregando complexidade aos debates. (Imagem 3) 
Imagem 3. Convidados Luis Filipe Macedo e João Novaes, juntamente com a coordenadora do projeto Vivianne Fleury

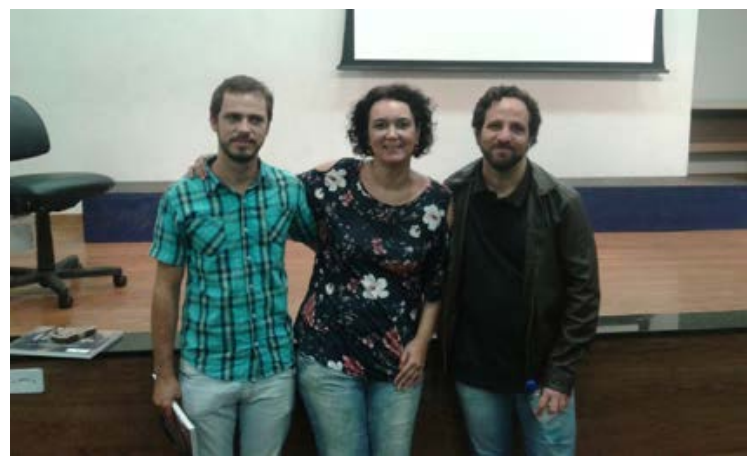

Com o decorrer de cada etapa os alunos desenvolveram pesquisas que resultaram em dissertações, poemas, peça teatral, cartazes, banners, todos de acordo com as temáticas abordadas ao longo do ano (Imagem 4). Todos os materiais realizados pelos alunos foram para exposição no dia do fechamento do projeto, além da apresentação da peça teatral e concurso de redação.

Imagem 4. Elaboração de materiais realizada pelos alunos ao longo do projeto.
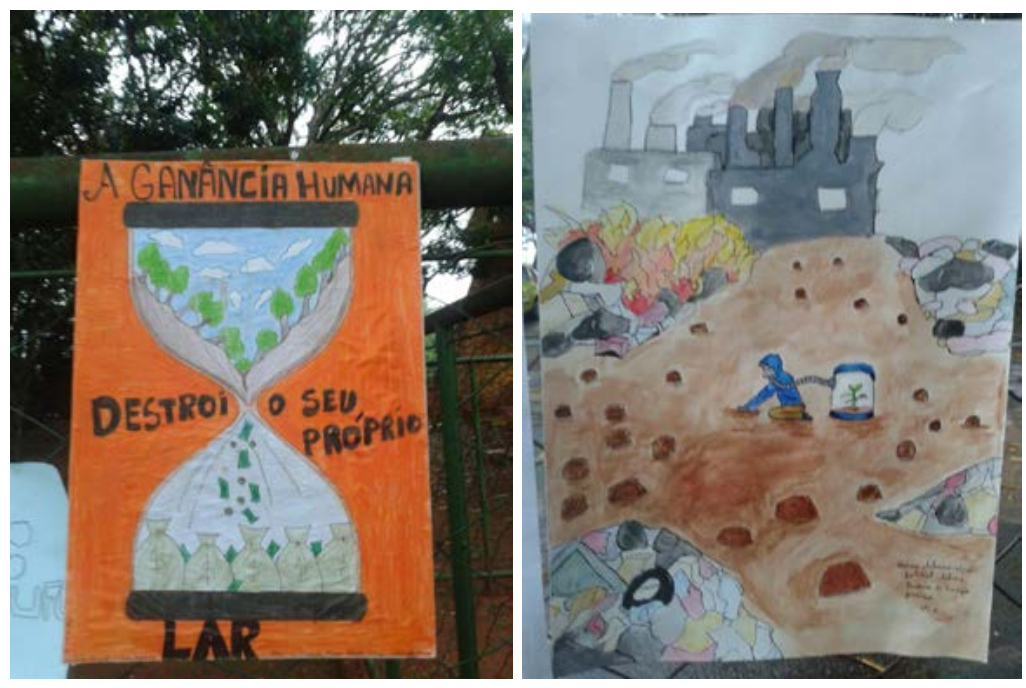

Considera-se que foi atingido o intuito primordial das ações que era a compreensão da intervenção humana no meio ambiente, podendo ser esta de forma desequilibrada e desarmônica, acarretando, assim, alteração da qualidade do meio ambiente. O despertar da responsabilidade ambiental foi fomentada durante todas as atividades, instigando os envolvidos a repensarem na relação entre natureza e sociedade, para que todos usufruam racionalmente e evitem um quadro caótico que já se delineia. 


\section{Conclusóes}

O projeto em geral teve o êxito desejado, uma vez que as atividades de modo geral seguiram de acordo com o planejado no processo inicial, ou seja, de apresentar as temáticas e instigar debates e questionamentos quanto à postura e responsabilidade socioambiental, considerando a participação assídua de alunos e comunidade em todas as atividades, através de colocações, questionamentos e manifestação de opiniões, elementos satisfatórios e positivos, segundo nosso parecer.

Além disso, as ações associadas à elaboração de materiais que são frutos dos aprendizados permitiram que os alunos fixassem e explorassem os conteúdos durante a execução dos projetos, além de despertar um olhar crítico. Em contrapartida o processo de aprendizagem é constante e o projeto ainda está apenas em sua fase inicial, a mudança comportamental e construção de valores são processos que se consolidam com o decorrer do tempo, sendo assim, o projeto terá continuidade em 2018.

\section{Referências}

ARAÚJO, Maria Inêz de Oliveira. A universidade e a formação de professores para a educação ambiental. Revista brasileira de educação ambiental / Rede Brasileira de Educação Ambiental. - n. 0 - Brasília: Rede Brasileira de Educação Ambiental, 2004.

CARVALHO, Isabel Cristina de Moura. Qual educação ambiental? Elementos para um debate sobre educação ambiental e extensão rural. Agroecologia e Desenvolvimento Rural Sustentável, Porto Alegre, v.2, n.2, abr./jun.2001.

DIAS, G. F. Educação Ambiental: Princípios e práticas. 3a ed.. São Paulo: Gaia, 1994a. 400p. ISBN 85-85351-09-8.

REIGOTA, M. Desafios à educação ambiental escolar. In: JACOBI, P. et al. (orgs.). Educação, meio ambiente e cidadania: reflexões e experiências. São Paulo: SMA, 1998. p.43-50.

JACOBI, P. et al.(org.). Educação, meio ambiente e cidadania: reflexões

e experiências. São Paulo: Cortez, 1997. P.384-390. Dispon'vl em: < http://

atividadeparaeducacaoespecial.com/wp-content/uploads/2014/09/cidadaniaesustobriga. pdf> Acesso: 21/06/2017.

PEDRINI, Alexandre de Gusmão. Educação Ambiental: reflexões e práticas contemporâneas. Rio de Janeiro: Vozes, 1998.

MINISTÉRIO DO MEIO AMBIENTE - AMMA. Declaração de Tbilisi. Disponível em: <http://www.mma.gov.br/port/sdi/ea/deds/pdfs/decltbilisi.pdf > . Acesso: 21/06/2017.

DIAS, G. F. Educação Ambiental: Princípios e práticas. 3a ed.. São Paulo: Gaia, 1994a. 400p. ISBN 85-85351-09-8. 